\title{
WIJZEN DE TEGENWOORDIGE ZEDEN EN GEWOONTEN DER BATAKS NOG SPOREN AAN VAN EEN OORSPRONKELIJK MATRIARCHAAT?
}

D O O R

\section{J. H. ME E R W'A L D T.}

Door het hoofd van gewestelijk bestuur der residentie werd ons voor eenigen tijd geleden de brochure over "De verbreiding van het matriarchaat op Sumatra" van den hoogleeraar Dr. G. A. Wilken, uitgegeven door het Kंoninklijk Instituut voor de taal-, land- en volkenkunde van Ned. Indië, toegezonden met het verzoek, het daarin behandelde onderwerp nader toe te lichten. Met genoegen voldoen wij daaraan, doch moeten, eer wij daartoe overgaan, doen opmerken, dat ons zulks alleen mogelijk is voorzoover het onderwerp betrekking heeft op de. Bataks, hetgeen uit den aard van onzen werkkring wel als van zelf spreekt.

De geachte schrijver van bovengenoemde brochure wijdt aan de gestelde vraag de blz. 28-33 en beantwoordt haar volkomen bevestigend. "Duidelijke bewijzen", lezen wij op blz. 28 , "ontmoet men echter bij de Bataks, dat zij voorheen deze instelling (het matriarchaat) hebben gehad." Een drietal gronden worden verder daarvoor aangevoerd. Naar onze meening kunnen wij geen daarvan laten gelden; voorzoover onze kennis van taal en zeden der Bataks reikt, kunnen wij in de door den heer Dr. Wilken aangehaalde feiten geen spoor van het matriarchat zien; veelmeer vloeien zij geheel en al uit den agnatischen toestand voort. Doch laat ons Dr. Wilken's bewijzen aan eene nadere beschouwing onderwerpen.

Het eerste bewijs is van taalkundigen aard. "In het Daïrisch dialect noemen zij, die tot dezelfde marga, denzelfden stam behooren, elkander sĕnnina, letterlijk "moedergenooten." Wij nemen dit met Dr. Wilken 
op gezag van den heer van der Tuuk gaarne aan, maar kunnen tot verklaring van die uitdrukking niet uit de hoofdbron putten, omdat wij met Daïri-Bataks nooit in persoonlijke aanraking kwamen. Wij moeten ons dus bij gebrek aan beter aan het met die uitdrukking analoge in het Tobadialect houden, en hebben dan daar de uitdrukking dongan saina, welke eveneens moedergenooten beteekent, maar hier alleen gebezigd wordt door hen, die van dezelfde ondermarga zijn. Daarin ligt dus verschil. Immers de heer Wilken zegt (blz. 29), dat de ondermarga's elkander dongan saina noemen ter aanduiding hunner gemeenschappelijke afkomst, en dit is, naar wij uit zeer betrouwbare bron vernemen, niet het geval; integendeel noemen aan de boorden van het Tobameer, bakermat van het gansche volk, alleen zij, die tot dezelfde ondermarga behooren, zich onderling dongan saina. Wijst dan die uitdrukking niet op eene gemeenschappelijke stammoeder en op een vroeger bestaan hebbend matriarchaat? Op eene gemeenschappelijke stammoeder zeker, maar geenszins op het matriarchaat. Die uitdrukking is niet anders dan een gevolg van de polygamie. De ondermarga's, die tot dezelfde hoofdmarga behooren, zijn van een stamvader, maar veelal uit verschillende vrouwen gesproten, en hebben zich daarom gesplitst. Immers twee of meer vrouwen van denzelfden man verdragen zich gemeenlijk als kat en hond, en deze vijandschap gaat ook op de kinderen over, daar zij elkander steeds in hun erfdeel zoeken te benadeelen. Vandaar dan ook, dat zij zich gesplitst hebben, en dat zij, die van dezelfde ondermarga zijn, zich dongan saina noemen. Hoe zouden zij hunne nadere verwantschap ook anders hebben kunnen uitdrukken? Sä̈ma en ook sabutuha zijn de ondermarga's van dezelfde hoofdmarga, dus bleef er voor de leden derzelfde ondermarga niet anders over, dan zich onderling saina te noemen, wat echter geenszins op een matriarchale inrichting der familie wijst.

Naar analogie van het bovenstaande laat zich nu ook de Daïrische uitdrukking sěnnina wel verklaren. Dat zij, die tot dezelfde hoofdmarga behooren, elkander alzoo noemen, is daarbij geen bezwaar. Er zijn nog hoofdmarga's, wier namen op vrouwen als oorsprong wijzen, zooals Nai Pospos en Nai Rasaon, terwijl men ook van de marga's Borbor en Lontoeng zegt, dat zij oorspronkelijk Nai Borbor en Nai Lontoengan geheeten hebben. Het woordje nai is samengetrokken uit ina ni (moeder van) en beteekent Nai Pospos dus ina ni Pospos $=$ moeder van Pospos. Oppervlakkig beschouwd zou men dus ook uit deze stamnamen kunnen afleiden, dat het matri- 
archaat vroeger bij de Bataks heerschend geweest is. Naar de getuigenis der oudste thans nog levende Bataks en ook naar de getuigenis van hen, die de oudste zendelingen reeds als stokoude mannen hier aantroffen, hebben die namen alléen hun ontstaan te danken aan de vroeger bij de grooten des volks algemeen in zwang geweest zijnde polygamie.

Ook de uitdrukking dongan sabutuha wijst onzes inziens geenszins op het matriarchaat. Reeds hebben wij aangestipt, dat zij uitsluitend gebezigd wordt, om de af komst van een stamvader aan te duiden. Haar als een ouden naam voor een nieuwe zaak op te vatten, gelijk de heer Wilken wil, gaat niet wel aan, omdat de Bataks van oudsher eene geheel andere zienswijze ten opzichte van het aandeel van man en vrouw bij de voortplanting van hun geslacht gehad hebben, dan de Maleiers. Een slap en verwijfd Maleisch geslacht moge zich tevreden stellen met te zeggen: " ajam djam djantan tida berrtělor", de Batak weet te goed, dat van honderd kippen zonder haan geen kuiken ter wereld komt. Hij beschouwt zich dan ook op dat punt evenals op alle andere als de hoofdpersoon; de vrouw is voor hem slechts het onmisbaar medium, om tot nakomelingen te geraken, en indien hij te lang naar zijn zin daarop wachten moet, geeft hij zijne vrouw als een onnut instrument aan hare bloedverwanten terug, of hij neemt nog een tweede vrouw er bij, indien hij daartoe vermogend genoeg is. Dit laatste werd ook steeds gedaan, wanneer de eerste vrouw een aantal meisjes ter wereld gebracht had, zonder nog aan een zoon het leven geschonken te hebben. Ook dit karakteriseert den Batak, en doet het scherp uitkomen, dat naar zijne zienswijze in het mannelijk geslacht de kracht van het volk zit. Wij zien uit dien hoofde in de uitdrukkingen dongan sabutuha en morsabutuha niets anders dan een verbloemde spreekwijze, om het saäma of saompoe $=$ van een vader of van een grootvader nog scherper te doen uitkomen. Apala na morsabutuha $=$ werkelijk van een vader zegt de Batak, om het zoo scherp mogelijk uittedrukken, dat twee of meer personen broeders of zusters van een vader zijn, en zeker gebruikt hij deze uitdrukking, om andere te vermijden, die heel leelijk zouden zijn, op dezelfde wijze als bijv. in den bijbel van "lendenen" gesproken wordt. Trouwens de Batak bedient zich gaarne van verbloemde spreekwijzen, inzonderheid waar het op den echtelijken omgang ankomt. Zij bezitten dan ook tal van verbloemde uitdrukkingen, om te kennen te geven, dat een vrouw zich in gezegende omstandigheden bevindt, als daar 
zijn : djoemoedjoeng hoenik $=$ zij draagt curcuma op het hoofd, $n a$ manygora pamoero di ibana $=$ de wachters in het rijstveld roepen haar aan, $n a$ managam haroan $=$ zij verwacht een feest, of $n a$ managam tamoewe $=$ zij verwacht een gast, en andere meer. In geen van die uitdrukkingen gebruikt de Batak het woord butuha $=$ buik, integendeel vermijdt hij het steeds ten opzichte van eene vrouw van haar buik te spreken. Wij mogen dus hieruit wel de gevolgtrekking maken, dat het pantang $=$ verboden zou zijn, van dongan sabutuha te spreken indien daarbij eenigszins aan de moederschoot werd gedacht.

Ook op het gebruik van het woord toeboe (ontspruiten, ontkiemen, geboren worden, ontstaan) en de daarvan afgeleide vormen manoeboehon, mangintoeboe en pangintoeboe mogen wij wijzen, want het doet evenzeer duidelijk zien, dat de Batak zich zelf als de hoofdpersoon bij de voortplanting van zijn geslacht beschouwt.

Zijne eigene kinderen noemt hij toeboengkoe, om ze van broerskinderen, die hij ook als zijne kinderen aanziet, te onderscheiden. Evenzoo zegt hij van zijne eigene kinderen no hoetoeboehon $=$ zij zijn door mij ter wereld gebracht, en noemt zich zelf ten opzichte van zijne kinderen pangintoeboe $=$ de voortbrenger.

Wij kunnen er daarom geenszins meê instemmen, wanneer de heer Wilken zegt, dat de boven verklaarde uitdrukkingen zich alleen onder het matriarchaat kunnen gevormd hebben. Ons leveren zij veelmeer het bewijs, dat het patriarchaat bij de Bataks het oor-. spronkelijke is geweest. Zij doen het bewustzijn van mannelijke kracht en waarde, dat bij de Bataks zoozeer ontwikkeld is, ten sterkste uitkomen.

Als tweede bewijs voor de oorspronkelijkheid van het matriarchaat bij de Bataks voert de heer Wilken aan "de bepalingen omtrent de indeeling bij en de vrijstelling van de verplichte diensten ten behoeve van de hoofden." Het is volkomen juist, dat alleen gehuwde mannen tot die diensten verplicht gerekend worden, zoodat een man, die zijne vrouw door den dood verloor, vrijgesteld werd, terwijl eene weduwe, wanneer zij namelijk, gelijk de heer Wilken terecht zegt, een volwassen, ongehuwden zoon had, steeds als tot die diensten verplicht werd aangezien. Maar mogen wij daaruit nu besluiten, dat het al of niet ripe zijn eenigszins van de vrouw af hangt, gelijk de heer Wilken doet? In geenen deele. Immers de heer Wilken heeft bij het maken van zijne gevolgtrekking geheel en al uit het oog verloren, dat er een volwassen, ongehuwde zoon in huis 
zijn moet, om het gezin in stand te doen blijven, hoewel hij zelf niet zonder nadruk daarop wijst. Het zwaartepunt ligt dan ook volstrekt niet bij de vrouw, maar wel degelijk bij het aanwezig zijn van dien volwassen, ongehuwden zoon. Alleen omdat die er is en bij den dood zijns vaders hoofd van het gezin werd, blijft de ripe als zoodanig in stand. Er is dus hier volstrekt geen regeling "zoo vreemd aan het wezen en het karakter van de agnatische verwantschap" te bespeuren; veel meer vloeit deze regeling geheel en al uit de zuiverheid van den agnatischen toestand voort.

Laat ons ter nadere verklaring daarvan den blik een weinig dieper in het Bataksche familieleven slaan. Wanneer de Batak eene vrouw koopt, dan wordt deze daardoor tevens ook het eigendom van de marga, waartoe de man behoort, resp. het eigendom van hen, die de man in engeren zin zijn dongan sabutuha noemt. Het gevolg daarvan is, dat de vrouw bij overlijden van haren man even als alle andere eigendommen op den naasten erfgenaam overgaat. Was het door den dood des mans ontbonden huwelijk met een zoon of zonen gezegend, dan wordt de moeder het eigendom harer kinderen, onverschillig of dẹze al dan niet mondig zijn. Deze toestand is voor de moeder verreweg de verkieslijkste, want daarbij hlijft het gezin voortbestaan, en niemand kan haar iets ontnemen noch van de roerende noch van de onroerende goederen, die haar man bezeten heeft, omdat alles het eigendom is van haar zoon of zonen, over welke zij de voogdij uitoefent. Zijn de zoons volwassen en huwen zij, dan ontvangen zij hun erfdeel en de moeder blijft als weduwe bij een van hen. Huwt een der zoons, dan blijven zij toch meestal allen bij elkaâr en vormen eene ripe. Zulk eene weduwe blijft dan ook meestal in haren weduwstaat, ten minste indien hare zoons reeds zoover zijn, dat zij mede op het veld kunnen werken, en dan is de Bataksche vrouw over het algemeen laat mij maar zeggen mans genoeg, om hare huishouding te bestieren en zelfs voor de rechten harer onmondigen op te komen, indien deze mochten gekrenkt worden. Geheel anders echter is het, wanneer een huwelijk door den dood des mans ontbonden wordt, zonder dat er mannelijk oir aanwezig is. Dan wordt de weduwe, of zij dochters heeft of niet, het eigendom van den naasten erfgenaam of erfgenamen, zij het van haar mans broeders of hunne zonen, en deze kunnen met haar geheel naar willekeur handelen. Een van hen kan haar tot vrouw nemen, of zij kunnen haar aan een ander van hunne marga uithuwelijken. Heeft zij dochters, die de moederlijke zorg nog be- 
hoeven, dan laten de erfgenamen haar wel met hare kinderen bij elkaâr en mag zij ook een deel van de roerende en onroerende goederen behouden, om in het onderhoud harer dochters te voorzien. Later echter, wanneer hare dochters in het huwelijk getreden zijn, en zij zelf alleen gebleven is, kan zij een goed heenkomen zoeken. Het ongelukkigste echter is de vrouw er aan toe, die, reeds welbedaagd en kinderloos zijnde, weduwe wordt, want dan wordt zij eenvoudig met niet meer dan het slechtste kleedingstuk om het lijf weggezonden en kan hare eigene nabestaanden gaan opzoeken. Edoch die toestand bestaat nog alleen, waar het heidendom of het mohammedanisme heerscht. Onder den invloed van het Christendom is het lot der kinderloos achterblijvende weduwe in dier voege verbeterd, dat haar een door de hoofden bepaald deel zoowel van de roerende als van de onroerende goederen in leenbruik moet worden toegekend.

Uit het bovenstaande blijkt voldoende, dat het niet aangaat te zeggen, dat het Bataksche gezin staat of valt met de vrouw. Een gezin is slechts daar, waar man en vrouw te zamen zijn, of waar bij ontstentenis van den man de zoon in de plaats zijns vaders treedt. Daaruit volgt echter ook, dat de man zonder vrouw evenmin een gezin kan vormen, zoodat ook bij overlijden van de vrouw het gezin wordt opgelost, en de man, nu geen pater familias meer zijnde, ook van de verplichte diensten ten behoeve van zijn hoofd wordt vrijgesteld. De oorzaak daarvan is niet moeilijk te vinden, wanneer men eenigszins met de Bataksche huishouding bekend is. Twee dingen zijn er, die de Batak absoluut niet kan, t. w. zijn rijstveld wieden en kleine kinderen verzorgen. Dat is het werk zijner vrouw, en daar hij nu, wanneer hij zijne vrouw door den dood verliest, geen andere vrouwelijke hulp voor zijn gezin kan krijgen, spreekt het van zelf, dat het gezin zich voor korten of langen tijd moet oplossen. De man trekt met zijne kinderen bij zijne ouders in, wanneer hij die nog heeft, en vormt met deze weêr een gezin, of hij brengt zijne kinderen bij zijne broeders of zusters onder en laat ook zijn rijstveld aan deze over, terwijl hij zelfs dikwijls een zwervend leven gaat leiden. De Batak, die zijne vrouw door den dood verliest, is er dus rampzalig aan toe, en heeft in dat geval geen beteren troost dan het bezit van geld of goed, waarvoor hij zich direct weêr eene levensgezellin kan verschaffen. Hij kan dan ook zonder het minste bewustzijn van onwelvoegelijkheid aanstonds, nadat hị zịjne vrouw ten grave gedragen 
heeft, over de koopsom eener andere gaan onderhandelen. Heeft hij echter geen geld en ook geen kans, het van zijne naaste bloedverwanten te krijgen, dan voelt hij zich diep ongelukkig en doet gelijk boven gezegd is. Dan is hij een zwerver, gelijk hij zelf zegt, en daarom een man, op wien niet te rekenen valt, en dit is de oorzaak, dat men hem in de hoeta niet meer meêtelt en van alle verplichte diensten ook van de rodi of heerendienst van het gouvernement ontslaat.

Wịj vinden dus ook hierin geen spoor van het matriarchaat, maar veel meer ook hier bewijzen voor het oorspronkelijke van den agnatischen toestand.

Wij komen nu tot de beschouwing van hetgeen door den heer Wilken als derde bewijs voor een oorpronkelijk matriarchaat bij de Bataks wordt aangevoerd. De zaak op zich zelf is volkomen juist; de Batak neemt bij voorkeur de dochter van zijns moeders broeder tot vrouw, terwijl hij de dochter van zijns vaders zuster niet nemen mag. Wij mogen het eerste echter niet als een vaststaanden regel opvatten, want de huwelijken tusschen neef en nicht staan verreweg in de minderheid. Immers er is nog al veel kans bij, dat zulke verbintenissen kunnen gesloten worden, want het moet dan juist zoo uitkomen, dat de broeder eene dochter en de zuster een zoon heeft, die elkanders sapi (woordelijk = rijm) en ook elkander wederzijds genegen zijn. Daar nu echter aan zulke verbintenissen tusschen neef en nicht de voorkeur gegeven wordt, spreekt het wel van zelf, dat het als eene veronachtzaming der familiebetrekking wordt aangemerkt, indien iemand een ander tot vrouw neemt, terwijl hij eene nicht (borvu ni-datulang) heeft, die wat ouderdom of lichamelijke ontwikkeling betreft bij hem past. In zulk een geval brengt hij zijn oom een geschenk en zoekt dezen door goede woorden er van te overtuigen, dat hij geenszins uit minachting der familiebanden alzoo handelt. Het is dus juist geen wet, maar een ingeburgerde gewoonte, waarop moet worden geacht, om den vrede te bewaren. Ook wat de heer Wilken over het huwelijk tusschen neef en nicht (broerszoon en zustersdochter) zegt, is volkomen juist. Zulks geldt als bloedschande even als het huwelijk tusschen zoon en dochter van twee broeders of de verboden omgang van eigen broeder en zuster. Dit laatste voornamelijk is het, wat het eerste zonderling doet schijnen, en de verklaring er van is ook niet gemakkelijk. De heer Wilken zoekt haar in het oorspronkelijk matriarchaat; zien wij of zij de proef kan doorstaan. Om niet in langdradige herhalingen te 
vervallen, verwijzen wij naar hetgeen de heer Wilken blz. 33 zijner brochure schrijft. "De broeder zag even als tijdens het matriarchaat op de zusterskinderen als op zijne eigen kinderen neêr", lezen wij, "terwijl de broerskinderen voor de zuster vreemden bleven." Toegegeven, dat dit juist ware, maar dan rijst bij ons onwillekeurig de vraag op: Hoe kon dan de broeder zijne dochter ter vrouw geven aan iemand, dien hij als zijn eigen zoon beschouwt? Dat zou immers bloedschande zijn. Volgens de regelen van het matriarchaat toch is het juist de zusterszoon, dien de oom als eigen zoon aanziet, terwijl bij de Bataks juist het omgekeerde het geval is. Daar ziet de oom van moederszijde de zonen zijner zuster als vreemden aan, daar zij tot een andere marga behooren, maar de dochters zijner zuster gelden hem als eigene. Vandaar dan ook, dat hij zijne dochter aan den zusterszoon ter vrouw kan geven, terwijl zijn eigen zoon geene zustersdochter tot vrouw nemen mag, veelmeer ontvangt hij, wanneer er eene dochter zijner zuster uitgehuwelijkt wordt, een deel van de boli (Angkola) of sinamot (Toba), welk deel oepa tulang wordt genoemd. Ons dunkt, dat hieruit duidelijk genoeg blijkt, dat het aannemen van een oorsprokelijk matriarchaat ons geen voetstap verder brengt tot opheldering van het feit in kwestie. Integendeel laat zich de oorspronkelijkheid van het patriarchaat veeleer daarmeê bewijzen. Waarom toch kan de Batak de zoons zijner zuster niet en de dochters wel als eigen kinderen aanzien, daar zij toch beiden tot een andere marga behooren? Hierop kan niet anders geantwoord worden dan dat de zoons zijner zuster geheel en al tot de marga huns vaders behooren, d. w. z. als mannelijke leden dier marga ook geroepen zijn tot de instandhouding er van bij te dragen. Daarom kan hun tulang ook volstrekt niet het minste recht van bloedverwantschap op hen doen gelden, hij kan ze alleen nog door aanverwantschap aan zich verbinden, en dit doet hij door hun zijne dochters tot vrouwen te geven. Maar ook van de andere zijde heeft men die verbintenis gaarne, omdat de neefs zijns oomsdochter altoos een weinig goedkooper krijgt dan een ander, en ook omdat de oom aan de vereenigde smeekingen van eigen dochter en neef geen weerstand kan bieden, en zijne huwelijksgift vergrooten moet. Met de zusters dochters is het echter anders. Die zijn reeds bestemd, om aan een andere marga over te gaan, en daar hij nu reeds voor zijne zuster sinamot ontvangen heeft, breidt hij dat recht ook nog tot hare dochters uit, hij beschouwt ze als zijne eigene en ontvangt nu, wanneer zij uitgehuwelijkt worden, 
zijn oepa tulang. Zijn zwager, de vader der meisjes, heeft daarbij geen schade, want hetgeen hij moet hebben, wordt altijd het eerst bepaald, en dan komt de oepa tulang er nog boven op. Daarom duren de onderhandelingen over een huwelijk vaak zeer lang.

Met den vader van het meisje is de zaak gewoonlijk spoedig beklonken, maar dan eerst komen de porlamboeng d. i. "de ter zijde staanden" namelijk de ooms van vaders en moederszijde, om zooveel mogelijk voor zich er uit te kloppen, en kunnen dan vaak zeer hardnekkig zijn, terwijl er aan de zijde van den bruidegom niet veel geld meer over is. Wij zien dus, dat deze adat alleen op welbegrepen eigenbelang rust. Toch mogen wij daaruit niet besluiten, want hij ontvangt na lang loven en bieden vaak niet meer dan dat het den Batak daarbij alleen om dat weinige geld te doen is; een paar ringgit (Spaansche matten). Neen, de Batak ziet en zoekt zijn voordeel veel verder. Door de dochters zijner zuster als eigene te beschouwen, blijft hij niet alleen met hen in bloedverwantschap, wanneer zij aan een andere marga door het huwelijk overgaan, maar hij komt ook met deze marga zelf in aanverwantschap, en dat beteekent voor hem vermeerdering van aanzien en macht. Een groote aanverwantschap (tondong) te bezitten, is van veel gewicht, want dat is de bron van hulp in tijd van nood. Daarom zoekt hij dan ook steeds zijne aanverwantschap te bevestigen en uittebreiden en moeten ook de kinderen van broers en zusters daartoe meewerken. Om de eenmaal bij het huwelijk zijner zuster aangeknoopte aanverwantschap te bestendigen, geeft hij zijne dochters den zonen zijner zuster tot vrouwen, en om zijne aanverwantschap nog tot andere marga's uittebreiden, beschouwt hij de dochters zijner zusters als zijne eigene, en neemt ze niet voor zich zelf tot schoondochters.

Wij noemden dus deze adat terecht een gebruik, dat uit welbegrepen eigenbelang voortvloeit. Immers, indien hij de dochters zijner zuster eens niet als eigen kinderen beschouwde en ze tot schoondochters nam, dan zou hetgeen van hem uit kon gaan, om zijn rijkdom en aanzien te vermeerderen, eenvoudig tot hem terugkeeren, en dat komt hem zoo verkeerd voor als "water dat tegen den berg oploopt" (marsuntjang do aek pahulu) zooals de Angkolaër zegt, hetgeen in Toba wordt uitgedrukt met pasoehar toetoer $=$ de familiebetrekking omkeeren. Zijn dochter (zustersdochter) zou zijn schoondochter worden en dus ook zijn eigen zoon zijn schoonzoon. Dat is hem al te averechts.

Toch is het niet altijd zoo geweest. Naar de getuigenis veler 5e Vo'g. VII. 
Bataks was het in vroegere tijden, toen het volk nog klein was, ook geoorloofd, de dochter van vaders zuster tot vrouw te nemen, en het schijnt nog al moeite gekost te hebben, dit gebrnik op te heffen. Dat bewijzen de legenden (toeritoerian), die verhalen, hoe de wraak der goden hen getroffen heeft, die zulk eene echtverbintenis aangegaan hadden. Zoo bijv. de beeldjes, die van onder tot boven den toenggal panaloean versieren, zijn niet anders dan een plastische voorstelling van de lotgevallen van zulk een echtpaar, dat door de wrakk der goden overal vervolgd wordt. Ook ligt er, naar men ons mededeelt, aan den voet van de westelijke helling van den berg Si Himon een groote zwarte steen, die de gedaante heeft van twee op elkander liggende menschen, en waarop ieder voorbijganger een klein offer brengt van tabak of napoeran of van hetgeen hij anders bij zich heeft. Dat is Datoe Poring en zijn zuster (tantes dochter), welke aldaar door den bliksem getroffen zijn, zegt men, juist toen zij met elkander in ongeoorloofde gemeenschap waren. Zulke verhalen zijn toch zeker net geen ander doel verdicht, dan om een ingeworteld gebruik bij het volk gehat te maken. Dat daartoe zelfs de dreigende wraak der goden noodig was, bewijst hoe moeielijk het volk zijn eenmaal aangenomen adat weer loslaat.

Daarom dan ook is het ons moeielijk aan te nemen, dat het matriachaat ooit bij de Bataks zou geheerscht hebben en door het thans heerschende patriarchat verdrongen zijn, èn dit wordt ons daardoor geheel onmogelijk gemakt, dat wij in de tegenwoordige adat ook hoegenaamd niets kunnen vinden, hetwelk op een oorsponkelijk matriarchat wijst. Immers alles, wat de heer Wilken als bewijs voor het oorspronkelijke van het matriarchaat aanvoert, kewijst bij nadere beschonwing slechts het tegendeel, en andere daarop wijzende gebruiken zijn noch ons noch onzen oudsten collega's bekend. Trouwens zulk een tolale omkeer in de adat zou nooit anders dan onder vreemden (in casu Maleischen) invloed hebben kunnen plaats grijpen. Dit is echter onmogelijk, ten eerste omdat de Maleiers zelf de matriarchale inrichting der familie hebben en ten andere omdat de Bataks tot hun geluk grootendeels voor dien invloed zijn bewaard gebleven. Wij voor ons beschouwen dan ook het matriarchat op Sumatra als iets, dat specifiek bij de Maleiers thuis behoort, en kunnen ook de meening van den heer Wilken ten opzichte van die volken op dit eiland, die reeds min of meer onder Maleischen invloed gekomen zijn, en bij welke zoowel de agnatische toestand als het matriarchaat gevonden wordt, niet deelen. Ons komt het veel waarschijnlijker 
voor, dat ook bij hen even als bij de Bataks de agnatische toestand oorspronkelijk is en het matriarchaat zich onder Maleischen invloed ingang bij hen verschaft heeft. Daarover meer licht te verspreiden, blijft de taak van hen, die met die volken in aanraking komen. Wij beschouwen onze taak voor ditmaal als volbracht en hopen met dit opstel ook iets tot meerdere kennis van de inrichting der familie bij het volk, aan wiens welzijn wij ons leven wijden, te hebben bijgedragen.

Pansoernapitoe, Silindoeng, 9 Juli 1889. 